\title{
Association Between Hearing Loss And Cauliflower Ear in Wrestlers, a Case Control Study Employing Hearing Tests
}

\author{
Pardis Noormohammadpour ${ }^{1,2}$; Mohsen Rostami ${ }^{1}$; Ruhollah Nourian ${ }^{1}$; Mohammad Ali \\ Mansournia ${ }^{3}$; Saeed Sarough Farahani ${ }^{4}$; Farzin Farahbakhsh ${ }^{1}$; Ramin Kordi ${ }^{1,5,{ }^{*}}$ \\ ${ }^{1}$ Sports Medicine Research Center, Neuroscience Institute, Tehran University of Medical Sciences, Tehran, IR Iran \\ ${ }^{2}$ Department of Sports and Exercise Medicine, School of Medicine, Tehran University of Medical Sciences, Tehran, IR Iran \\ ${ }^{3}$ Department of Epidemiology and Biostatistics, School of Public Health, Tehran University of Medical Sciences, Tehran, IR Iran \\ 4 Department of Audiology, Faculty of Rehabilitation, Tehran University of Medical Sciences, Tehran, IR Iran \\ ${ }^{5}$ Spine Division, Noorafshar Rehabilitation and Sports Medicine Hospital, Tehran, IR Iran \\ ${ }^{*}$ Corresponding author: Ramin Kordi, Sports Medicine Research Center, Tehran University of Medical Sciences, Tehran, IR Iran. Tell: +98-2188630227-8, Fax: +98-2188003539, \\ E-mail: ramin_kordi@tums.ac.ir
}

Received: December 2, 2014; Revised: February 6, 2015; Accepted: February 25, 2015

\begin{abstract}
Background: According to anecdotal findings, some wrestling coaches and wrestlers believe that cauliflower ear might lead to hearing loss. Our preliminary study showed that the prevalence of hearing loss reported by the wrestlers with cauliflower ear is significantly higher than this rate among wrestlers without cauliflower ear. To the best of our knowledge, no other study has confirmed this finding employing hearing tests.

Objectives: To evaluate and to compare the prevalence of hearing loss among wrestlers with and without cauliflower ears employing hearing tests.

Patients and Methods: The subjects were randomly selected form 14 wrestling clubs in Tehran. Subjects were 201 wrestlers with cauliflower ears (100 wrestlers with one cauliflower ear and 101 wrestlers with two cauliflower ears) and 139 wrestlers without cauliflower ears. All the participants in this study were interviewed to collect information on demographic factors and medical history of risk factors and diseases related to hearing loss. The subjects in both groups underwent otoscopic and audiologic examinations.

Results: Audiometric examination results at the frequency range of $0.5-8 \mathrm{KHz}$ showed that the prevalence of hearing loss among cauliflower ears was higher than this rate among non-cauliflower ears. Also, the percentage of positive history of ear infections among cauliflower ears (8.4\%) was about two times more than this finding among non-cauliflower ears (4.9\%). This difference tended to be significant (OR: $1.86, \mathrm{P}=0.06,95 \% \mathrm{CI}: 0.98-3.53$ ).

Conclusions: To the best of our knowledge, this is the first study showing that the prevalence of hearing loss among cauliflower ears is higher than this rate among non-cauliflower ears confirmed by audiological tests. This emphasizes that, more preventive measures such as mandatory ear gear for wrestlers are required.
\end{abstract}

Keywords: Hearing Loss; Wrestling; Hearing Tests

\section{Background}

In some sports, such as boxing, rugby, judo and wrestling, a typical deformity of external ear identified as cauliflower ear has been reported (1). Cauliflower ear can be observed widely among wrestlers in some regions such as Asian countries (2).

The major tissue in the texture of pinna is cartilage covered by perichondrium, subcutaneous tissue and skin. Direct blunt trauma or continuous abrasion of the pinna might bring about accumulation of blood and serum in the space between perichondrium and cartilage (3-6); this hematoma might lead to cartilage necrosis through reduction of blood flow into the tissue (7). Cartilage necrosis and fibroneocartilage formation in the area results in deformity of the pinna and may result in the loss of cartilaginous support for the shape of the pinna resulting in a "cauliflower ear" or "wrestler's ear" deformity.
In the United States, it was reported that 39\% of collegiate wrestlers had cauliflower ear in 1989 (8). According to the rules of NCCA, employing ear protector devices is mandatory for all wrestlers in both training sessions and competitions (9). However, accordance to the international wrestling regulations, ear gears are not obligatory for wrestlers except for cadet and junior female wrestlers. It is reported that using ear protectors may be followed by relative reduction of sport injuries of the ear (8).

Wrestling has been a symbol of power and virility for the people in a number of countries. Cauliflower ear is recognized as a "badge of courage" in these regions. Therefore, wrestlers refuse to treat their ear hematoma in order to intentionally develop a cauliflower ear (10). As an example Iranian wrestlers do not employ any kind of ear protection; in addition, most of Iranian wrestlers avoid treatment of

Copyright ( 2015 , Sports Medicine Research Center. This is an open-access article distributed under the terms of the Creative Commons Attribution-NonCommercial 4.0 International License (http://creativecommons.org/licenses/by-nc/4.0/) which permits copy and redistribute the material just in noncommercial usages, provided the original work is properly cited. 
Noormohammadpour P et al.

their ear injuries because they believe that cauliflower ear can be considered a symbol of honor for wrestlers (2).

In the literature, cosmetic problems including protrusion and distortion of the ear have been reported as the major direct complication of cauliflower ear in wrestlers (11). In addition, it has been reported that in cases which deformity of the ears continue to the external canal of the ear, it could lead to the obstruction of the external canal (12), and hearing loss would be expected. Deformity of the external canal of the ear might also lead to irregularity in normal wax expelling and thereby increase the rate of ear infections (13).

A previous survey which employed a questionnaire based interview, showed that $44 \%$ of wrestlers in Tehran have cauliflower ear. Of the wrestlers with cauliflower ear, $11.5 \%$ (95\% CI: $6.9 \%$ to $16.2 \%$ ) reported that they feel hearing loss, while only $1.8 \%$ ( $95 \%$ CI: $0.1 \%$ to $3.5 \%$ ) of wrestlers without cauliflower ear reported hearing loss. This study was a cross sectional survey on different wrestling clubs in Tehran and no audiometric test was performed to evaluate the intensity of hearing loss in wrestlers (2).

\section{Objectives}

Anecdotal data shows that some wrestlers and their coaches believe that cauliflower ear might lead to hearing loss (2). To the best of our knowledge, no study has evaluated the hearing loss as a possible consequence of ear injuries leading to cauliflower ear in wrestling. In this case-control study, we aim at finding the connection between cauliflower ear and hearing loss employing audiometric tests.

\section{Patients and Methods}

This was a case-control study. The subjects were wrestlers between 15 to 25 years of age, with and without cauliflower ear, which were selected from 14 wrestling clubs in Tehran. All chosen subjects were wrestling regularly (not less than 3 sessions per week) for at least 1 year. Exclusion criteria were defined as employment in jobs with noise pollution, history of using ototoxic drugs, or congenital ear diseases either in the wrestlers or their first degree relatives.

Demographic data, history of either previous disease related to hearing loss, probable symptoms of hearing loss and risk factors for hearing loss (including history of noise overexposure, use of ototoxic drugs) were asked from subjects via an interview.

Examination of ears with an otoscope was performed for subjects in both cases and control groups. In this regard, the external canal and tympanic membrane of the wrestlers were observed carefully by an expert otolaryngologist and any obstruction in the external canal, perforation of tympanic membrane or other abnormalities were reported. Wrestlers in both groups underwent audiologic examinations including pure tone audiometry and impedance audiometry. These audiologic examinations were performed in a quiet place in each of the wrestling clubs but not in an audiometric test room.
Pure Tone Audiometry (PTA) was carried out for all wrestlers using a portable audiometer (Madsen DSA 84, Madsen Electronics, Copenhagen, Denmark). The hearing threshold at 0.5 to $8 \mathrm{KHZ}$ was assessed for the wrestlers; this range of frequencies was selected since it is reported as common speech frequencies $(14,15)$. A pure tone was delivered via headphones into the wrestlers' ears and the results of the test were recorded. According to standard protocols, PTA should be performed in a silent and soundproof environment. As we performed the test in sport clubs, we tried to provide a condition with minimum noise and we applied a TDH39 headphone, which its ear pads entirely covers the ear's auricles in order to decrease the effect of peripheral noises on testing and limits the auricles' collapse. To evaluate the middle ears of the wrestlers the following two tests were performed as a part of impedance audiometry for all wrestlers:

1) Tympanometry was performed by an expert audiologist to obtain wrestlers' ear tympanogram in both groups. In this regard, static compliance ranging from 0.3 to 1.6 cc and air pressure of the middle ear ranging from +50 to - 100 daPa were assumed normal (15);2) Acoustic reflex threshold was measured for all the wrestlers while data ranging 70 to $100 \mathrm{~dB}$ HL were considered as normal findings (16). If the test results showed normal "type A" tympanograms and normal acoustic reflexes, we would have ruled out conductive hearing loss, otherwise, wrestlers were referred for additional examinations and treatment.

Quantitative and qualitative variables were described as Mean (SD) and frequency (percentage) using SPSS 20 (SPSS Inc, Illinois, USA), respectively. To account for intrasubject correlation between ear level measurements, Generalized Estimating Equation (GEE) logistic regression was used to estimate the odds ratios (95\% CI) between cauliflower ear and hearing tests, adjusted for the potential confounding factors using Stata 11 (Stata Corp LP, College Station, USA).

In accordance with the written informed consent, signed by all the subjects before performing the study, wrestlers with complaint of hearing loss, were referred to audiology clinic for performing more sensitive diagnostic tests and also treatment. This study was also approved by the Ethical Committee of the Tehran University of Medical Sciences and study protocol conformed to the ethical guidelines of the 1975 Declaration of Helsinki.

\section{Results}

In total, 340 subjects, including 201 wrestlers with cauliflower ears (100 wrestlers with one cauliflower ear and 101 wrestlers with two cauliflower ears) and 139 wrestlers without cauliflower ears were investigated in this study. The distribution of cauliflower ears in wrestlers according to their age, and months of wrestling training is provided in Table 1.

Symptoms of hearing loss in wrestlers with and without cauliflower ear are showed in Table 2 . The percentage of positive history of ear infections among cauliflower 
ears (8.4\%) was about two times more than this finding among non-cauliflower ears (4.9\%). This difference tended to be significant (OR: 1.86, 95\% CI: $0.98-3.53, \mathrm{P}=0.06$ ). Also, results of otoscopic examination of external canal and tympanic membrane of the wrestlers' ears are presented in Tables 3 and 4.

Pure tone audiometry examination results at frequencies ranging from 0.5 to $8 \mathrm{kHz}$ showed that the frequency of hearing loss among cauliflower ears was higher than this rate among non-cauliflower ears. In our study, hear- ing loss was defined as above $25 \mathrm{~dB}$ HL decrease in hearing threshold according to basic values at each frequency (16). The results of pure tone audiometry at different measured frequencies are displayed in Tables 5 and 6.

Impedance audiometry, including tympanometry and acoustic reflex threshold results, showed that there is no significant association in odds ratio of clinically important parameters of the tests between cauliflower and non-cauliflower ears. The data of this audiologic test are provided in Table 7.

Table 1. Distribution of Cauliflower Ear Among Wrestlers Participating in the Study According to Their Age and Months of Wrestling Training a,b

\begin{tabular}{lccc}
\hline Variables & Months of Wrestling Training ${ }^{\mathrm{C}}$ & Age $^{\mathrm{c}}$ & Number $^{-}$ \\
\hline Wrestlers with one cauliflower ear & $68.1(35.9)$ & $20.5(2.5)$ & 100 \\
Wrestlers with two cauliflower ears & $73(32)$ & $21.4(3.2)$ & 101 \\
Wrestlers with no cauliflower ear & $51(38)$ & $20.6(2.7)$ & 139 \\
Total & & & 340
\end{tabular}

$\mathrm{a} \mathrm{n}=340$

b Statistically Significant: (Pvalue <0.05).

C Values are presented as Mean (SD)

\begin{tabular}{|c|c|c|c|}
\hline Symptoms of Hearing Loss & Wrestlers With No Cauliflower Ear, \% & Wrestlers With Cauliflower Ears, \% & P Value \\
\hline Feeling of hearing loss & 19.4 & 28.4 & 0.06 \\
\hline $\begin{array}{l}\text { Talking loudly during wres- } \\
\text { tling training }\end{array}$ & 22.3 & 27.4 & 0.291 \\
\hline $\begin{array}{l}\text { Hearing noise in ears or } \\
\text { head after course of train- } \\
\text { ing (Tinnitus) }\end{array}$ & 16.7 & 17.5 & 0.842 \\
\hline Sensing fullness of the ears & 13.8 & 16.4 & 0.506 \\
\hline
\end{tabular}

a Statistically Significant: (P value <0.05)

Table 3. Comparison of Abnormal Findings in Otoscopic Examination of External Canal of Cauliflower and NON-Cauliflower Ears a

\begin{tabular}{lccc}
\hline $\begin{array}{l}\text { Findings of Otoscopic Examination } \\
\text { (For Ear Canal) }\end{array}$ & Non-Cauliflower Ears, $\%$ & Cauliflower Ears, $\%$ \\
\hline Ear wax (little) & 15.9 & 16.6 & 0.75 \\
Ear wax (large) & 6.1 & 0.1 & 0.049 \\
Inflammation & 0 & 0 & 3.1 \\
\hline Deformity & 0 & 0.16 \\
\hline Canal stenosis & 0 & 0 \\
\hline
\end{tabular}

a Statistically Significant: (P value <0.05).

Table 4. Comparison of Abnormal Findings in Otoscopic Examination of Tympanic Membrane of Cauliflower and Non-Cauliflower Ears a

\begin{tabular}{lccc}
$\begin{array}{l}\text { Findings of Otoscopic Examination } \\
\text { (for Tympanic Membrane) }\end{array}$ & Non-Cauliflower Ears, \% & Cauliflower Ears, \% & P Value \\
\hline Retraction & 1.1 & 2 & 0.2 \\
Inflammation & 2.9 & 3.1 & 0.43 \\
Perforation & 3.0 & 3.4 & 0.19 \\
Plaque & 3.5 & 0.53 & 2 \\
\hline
\end{tabular}

a Statistically Significant: (P value <0.05). 
Noormohammadpour P et al.

\begin{tabular}{|c|c|c|c|c|c|c|c|}
\hline \multirow[t]{2}{*}{ Frequency, KHz } & \multicolumn{2}{|c|}{ Percentage of Ears With Hearing Loss, \% } & \multirow[t]{2}{*}{ OR } & \multirow[t]{2}{*}{ CI 95\% } & \multirow[t]{2}{*}{ PValue } & \multirow[t]{2}{*}{ Adjust $\mathrm{OR}^{\mathrm{b}}$} & \multirow[t]{2}{*}{ CI 95\% } \\
\hline & Non-cauliflower Ear & Cauliflower Ear & & & & & \\
\hline 0.5 & 11.9 & 24.8 & 1.99 & $1.33-2.98$ & $0.001^{\mathrm{C}}$ & 2.10 & $0.80-2.28$ \\
\hline $\mathbf{1}$ & 1.1 & 7.0 & 4.11 & $1.54-11.00$ & $0.005^{c}$ & 4.39 & $1.51-3.29$ \\
\hline 2 & 2.9 & 9.3 & 3.03 & $1.47-6.25$ & $0.003^{\mathrm{C}}$ & 3.11 & $0.96-2.19$ \\
\hline 3 & 9.0 & 15.2 & 1.66 & $1.03-2.67$ & $0.038^{\mathrm{C}}$ & 1.62 & $1.00-2.64$ \\
\hline 4 & 14.3 & 21.2 & 1.52 & $1.01-2.28$ & $0.045^{\mathrm{C}}$ & 1.45 & $1.50-6.45$ \\
\hline 6 & 15.1 & 29.1 & 2.20 & $1.50-3.23$ & $<0.001^{\mathrm{C}}$ & 2.23 & $1.60-12.26$ \\
\hline 8 & 8 & 12.3 & 1.3 & $0.80-2.24$ & 0.273 & 1.35 & $1.39-3.18$ \\
\hline
\end{tabular}

Table 6. Association Between Pure Tone Audiometry Results in Cauliflower Ears and Non-Cauliflower Ears at Different Frequencies a

\begin{tabular}{|c|c|c|c|c|}
\hline \multirow[t]{2}{*}{ Frequency, $\mathrm{KHz}$} & \multicolumn{2}{|c|}{ Mean (SD) } & \multirow[t]{2}{*}{ PValue $^{\mathrm{b}}$} & \multirow[t]{2}{*}{ CI 95\% } \\
\hline & Non-cauliflower Ear & Cauliflower Ear & & \\
\hline 0.5 & $22.59(4.89)$ & $24.78(7.28)$ & $0.001^{\mathrm{C}}$ & $1.14-3.35$ \\
\hline $\mathbf{1}$ & $20.11(3.44)$ & $21.27(5.09)$ & $0.006^{\mathrm{c}}$ & $0.33-1.97$ \\
\hline 2 & $19.99(4.47)$ & $21.64(6.21)$ & $0.002^{\mathrm{C}}$ & $0.59-2.52$ \\
\hline 3 & $21.66(7.84)$ & $23.16(8.45)$ & $0.041^{c}$ & $0.06-2.89$ \\
\hline 4 & $14.32(10.62)$ & $24.97(10.41)$ & $0.037^{c}$ & $0.11-3.62$ \\
\hline 6 & $23.61(10.24)$ & $26.56(11.47)$ & $0.002^{\mathrm{C}}$ & $1.03-4.55$ \\
\hline 8 & $21.23(7.63)$ & $22.75(10.41)$ & $0.046^{\mathrm{C}}$ & $0.03-3.00$ \\
\hline
\end{tabular}

a Abbreviations: CI, Confidence interval; SD, Standard Deviation.

$\mathrm{b}$ Adjusted for age, months of wrestling training, findings of otoscopic examination for tympanic membrane and noise over exposure.

${ }^{\mathrm{c}}$ Statistically Significant: (P value $\left.<0.05\right)$.

Table 7. Association of Abnormal Findings in Impedance Audiometry Test Between Cauliflower and Non-Cauliflower Ears a, b

\begin{tabular}{|c|c|c|c|}
\hline Factor of Measurement & OR & 95\% CI & P Value \\
\hline AR abnormal ${ }^{\mathrm{C}}$ & 0.67 & $0.36-1.26$ & 0.21 \\
\hline SA $>$ Normal $^{d}$ & 0.97 & $0.48-1.96$ & 0.93 \\
\hline SA $<$ Normal & 0.69 & $0.41-1.18$ & 0.17 \\
\hline TPP $<$ Normal $^{\mathrm{e}}$ & 2.54 & $0.23-28.1$ & 0.45 \\
\hline ECV $>$ Normal $^{f}$ & 3.97 & $0.87-18.1$ & 0.08 \\
\hline ECV $<$ Normal & 0.76 & $0.57-1.00$ & 0.06 \\
\hline
\end{tabular}

a Abbreviations: CI, Confidence Interval; OR, Odds Ratio.

b Statistically Significant: (Pvalue $<0.05)$.

c AR: Acoustic Reflex; (AR abnormal defined as AR $>110$ ).

d SA:Static Admittance; $(S A>$ Normal defined as $S A>1.7) ;(S A<$ Normal defined as $S A \leq 0.3)$.

e TPP: Tympanometric Peak Pressure (TPP $<$ Normal defined as TPP $<-100)$.

${ }_{\mathrm{f}} \mathrm{ECV}$ : Equivalent Canal Volume; $(\mathrm{ECV}>$ Normal defined as ECV $\geq 2)$; $(\mathrm{ECV}<$ Normal defined as $\mathrm{ECV}<0.9)$.

\section{Discussion}

To the best of our knowledge, this is the first study using audiologic tests at different frequencies, showing that the rate of hearing loss in wrestlers with cauliflower ear is higher than this rate among a control group of wrestlers without cauliflower ear. According to the results of PTA, hearing loss in all frequencies was significantly higher in cauliflower ears, except $8 \mathrm{kHz}$ frequencies. This might imply the importance of establishing preventive policies like mandatory use of ear gears.

Our finding supported results of previous study by Kordi et al. (2) which was a questionnaire based survey reporting significant differences between the rates of hearing loss in wrestlers with cauliflower ear $(11.5 \%)$ in comparison with wrestlers without cauliflower ear $(1.8 \%)(\mathrm{P}<0.05)$. 
The percentage of positive history of ear infections in wrestlers with cauliflower ear was about twice this rate among other group of wrestlers. Although this finding was not statistically significant, it could be considered as a possible reason for higher rate of hearing loss in cauliflower ears; thereby, ear infection prevention and on time treatment of ear infections may be recommended to prevent possible hearing loss in wrestlers. In this regard, partial obstruction of ear canal in cauliflower ears, may increase the probability of collection of pathogenic microorganisms in the ear canal and thereby increase the rate of infection in such ears. Direct trauma to the external ear, which happens in many contact sports such as wrestling, could indirectly damage the middle and inner ear as well.

To evaluate the effect of probable direct trauma and abrasions (as the major mechanisms leading to cauliflower ear in wrestlers) on the middle ear, the impedance audiometry was also performed for all wrestlers. According to the results of impedance audiometry, it was found that there is no significant relation in rate of abnormal acoustic reflex between cauliflower and non-cauliflower ears. As acoustic reflex test implies the intensity of stapedius through movement of tympanic membrane through generation of a loud sound. With respect to the mentioned findings, it may be concluded that there is no significant difference in the rate of diseases involving the stapedius muscle at its innervating nerve branch between the cauliflower ears in comparison with non-cauliflower ears, although some false negative conditions have also been described for this test (17-19).

According to the results of acoustic reflex test, even though cauliflower ears have suffered from more possible trauma, they do not have significant abnormalities in comparison with non-cauliflower ears. This finding maybe due to the type of trauma that usually leads to cauliflower ear since abrasion and blunt trauma can have less effect on the middle ear of the wrestlers due to its inner anatomical position as opposed to external ear.

As it is shown by the results, the static admittance in cauliflower ears was not found to be significantly higher than this rate in other group. It may imply that there is no significant connection between the severity of tympanic membrane tenacity of both groups leading to a non-significant relationship between the maximum compliance of the middle ear in the groups.

The number of wrestlers in case group with low Equivalent ear Canal Volume (ECV) was higher; in addition, the number of external canal stenosis found in cauliflower ears group was higher than non-cauliflower ears. These may be due to the role of fullness and stenosis of the canal in hearing loss of wrestlers with cauliflower ears $(20,21)$.

Considering the PTA and impedance results, it could be suggested that the resonant frequency of the external auditory canal has been changed, and this finding might be due to repetitive minor traumas to the cartilagous part of external canal. As a limitation of the study, the audiologic tests were performed in the wrestling clubs. While according to standard protocols, the tests should be done in a sound protected place. In this regard, a quite silent condition in a private room in the wrestling clubs was provided for performing the audiologic tests. Also, bone conduction testing was not performed on wrestlers, therefore, we could not differentiate the type of hearing loss (sensorineural, conductive, or mixed). However, due to the effect of environmental noises on the PTA data in $0.5 \mathrm{KHz}$, the percentage of wrestlers with hearing loss in this frequency has increased in both with and without cauliflower ear groups. If this frequency is ignored, the maximum number of wrestlers with hearing loss would be in the 4 and $6 \mathrm{KHz}$ frequencies (higher frequencies). Therefore, despite the importance of bone conduction audiometry for determination the type of hearing loss, it doesn't seem useful for interpreting the study's findings. This study was a retrospective study and more prospective studies might be needed to confirm our finding that hearing loss is a consequence of ear injuries that lead to cauliflower ears. However, within our limitations, we recommend that wrestlers wear ear protectors during wrestling training and promptly treat their ear hematoma.

\section{Acknowledgements}

Authors thank Ms. Fariba Nassaj (audiologist), for her competent technical assistance.

\section{Authors' Contributions}

All authors contributed equally to this paper.

\section{Funding/Support}

This research was supported by Tehran University of Medical Sciences and Health Services grant.

\section{References}

1. Kordi R, Maffulli N, Wroble RR, Wellby S, editors. Combat Sports Medicine.1ed. London: Springer; 2009.

2. Kordi R, Mansournai MA, Nourian RA, Wallace WA. Cauliflower Ear and Skin Infections among Wrestlers in Tehran. J Sports Sci Med. 2007;6(CSSI-2):39-44.

3. Ohlsen L, Skoog T, Sohn SA. The pathogenesis of cauliflower ear. An experimental study in rabbits. Scand J Plast Reconstr Surg. 1975;9(1):34-9.

4. Giffin CS. Wrestler's ear: pathophysiology and treatment. Ann Plast Surg. 1992;28(2):131-9.

5. Skoog T, Ohlsen L, Sohn SA. Perichondrial potential for cartilagenous regeneration. Scand J Plast Reconstr Surg. 1972;6(2):123-5.

6. Pandya NJ. Experimental production of "cauliflower ear" in rabbits. Plast Reconstr Surg. 1973;52(5):534-7.

7. Roy S, Smith LP. A novel technique for treating auricular hematomas in mixed martial artists (ultimate fighters). Am J Otolaryngol. 2010;31(1):21-4.

8. Schuller DE, Dankle SK, Martin M, Strauss RH. Auricular injury and the use of headgear in wrestlers. Arch Otolaryngol Head Neck Surg. 1989;115(6):714-7.

9. Klossner D. 2013-14 NCAA Sports Medicine Handbook. 24 ed. Indiana: The National Collegiate Athletic Association; 2013. The National Collegiate Athletic Association.

10. Reid DC. Sports Injury Assessment and Rehabilitation.New York: Churchill Livingstone; 1992.

11. Jones SE, Mahendran S. Interventions for acute auricular haematoma. Cochrane Database Syst Rev. 2004;(2):CD004166. 


\section{Noormohammadpour P et al.}

12. Yotsuyanagi T, Yamashita K, Urushidate S, Yokoi K, Sawada Y, Miyazaki S. Surgical correction of cauliflower ear. Br J Plast Surg. 2002;55(5):380-6.

13. Macdonald DJ, Calder N, Perrett G, McGuiness RG. Case presentation: a novel way of treating acute cauliflower ear in a professional rugby player. BrJ Sports Med. 2005;39(6):e29.

14. Yueh B, Shapiro N, MacLean CH, Shekelle PG. Screening and management of adult hearing loss in primary care: scientific review. JAMA. 2003;289(15):1976-85.

15. American Speech-Language-Hearing Association . Guidelines for manual pure-tone threshold audiometry. In: American SpeechLanguage-Hearing Association, editor. America: 2005.

16. Gelfand SA. In: Essentials of audiology. 3 ed. Hiscock T, editor. New York: Thieme; 2009.
17. Johns ME, Ruth RA, Jahrsdoerfer RA, Cantrell RW. Stapedius muscle function tests in the diagnosis of neuromuscular disorders. Otolaryngol Head Neck Surg (1979). 1979;87(2):261-5.

18. Bosatra A, Russolo M, Poli P. Modifications of the stapedius mus cle reflex under spontaneous and experimental brain-stem impairment. Acta Otolaryngol.1975;80(1-2):61-6.

19. Jones SE, Mason MJ, Sunkaraneni VS, Baguley DM. The effect of auditory stimulation on the tensor tympani in patients following stapedectomy. Acta Otolaryngol. 2008;128(3):250-4

20. Alencar AP, Iorio MC, Morales DS. Equivalent volume: study in subjects with chronic otitis media. Braz J Otorhinolaryngol. 2005;71(5):644-8.

21. Dalamagidis E, Boulti V, Mylonas A. Ear Injuries in Sports. Skul Base. 2009;19(S 02):A065. 